\title{
TECENDO OS FLUXOS DA MATÉRIA: EX-VOTOS NO CÍRIO DE NAZARÉ EM BELÉM DO PARÁ
}

\author{
Anselmo do Amaral Paes ${ }^{1}$
}

\section{A matéria da fé: ex-votos e o Círio de Nazaré}

Ex-voto (ex-voto suscepto - voto realizado) é o que se promete ao santo de devoção para se receber uma graça, ou o que se oferece por tê-la alcançado. Porém, a prática não é exclusiva do mundo católico, pois se encontra generalizada, tendo registro desde a remota antiguidade. Também chamadas de "promessas" (promissum) confundem-se como o próprio ato criador de prometer (Araújo, 2007: 154; Cascudo, 2012: 582-583; Frazer, 1982: 49, Monteiro, 2012: 175-189).

Zenia Escardó (2013) nos diz que o ex-voto dá o que pensar ${ }^{2}$. Seja por remeter à religiosidade popular, por investir nas dimensões estéticas e lúdicas que desafiam o "logocentrismo" de nossa sociedade, por expressar projetos de vida e expectativas sociais, assim como revelar dores, mazelas e necessidades no exercício de uma religiosidade popular (e suas profundas dimensões políticas) (Damatta, 1986), estes artefatos estão sempre apresentando novas "camadas", requisitando novas aproximações. Não só ação ou função, mas apropriação e reflexão sobre o mundo.

É sobre estes objetos sagrados que circulam durante o Círio de Nossa Senhora de Nazaré, e os muitos ângulos e diálogos a serem produzidos em busca de sua compreensão, que o presente artigo apresenta (longe de esgotar sua potencialidade) o "estado da arte" de minhas reflexões e inquietações sobre os mesmos, em diálogo com autores que buscam construir referenciais para a compreensão das relações paisagemcorpo-objeto. Assim, é necessário logo de início apresentar o Círio, aqui considerado a "paisagem devocional" que inclui os ex-votos.

Desde 1793 acontece em Belém do Pará (Brasil) um dos eventos religiosos católicos mais significativos do catolicismo brasileiro, o Círio de Nossa Senhora de Nazaré, cuja procissão principal que ocorre no segundo domingo de outubro, percorre as ruas da cidade, em várias romarias, missas e procissões no período de 15 dias $^{3}$. Em

\footnotetext{
${ }^{1}$ Sistema Integrado de Museus e Memórias, Pará, Brasil.

2 Aproximando-se da afirmação de Lévi-Strauss (1980) em sua reflexão sobre o totemismo quando este nos adverte de que: “(...)as espécies naturais não são escolhidas por serem 'boas para comer' mas por serem 'boas para pensar” (Lévi-Strauss, 1980: 165-166).

${ }^{3}$ O Círio tem sido intensamente analisado e apresentado nas últimas décadas sob várias ênfases: seja em suas dimensões geográficas e da mobilidade regional (Moreira, 1971), políticas, religiosas e rituais
} 
destaque a Trasladação e o Círio que recontam a lenda e milagre da Santa cuja imagem insistia em retornar ao local da descoberta, nos arredores de núcleo mais antigo da cidade.

O movimento das procissões ressoa o movimento da cidade em seu eixo de expansão do bairro da cidade velha, núcleo antigo da cidade, para a área do bairro de Nazaré e do centro para a área metropolitana, através da Rodovia BR 316 para a rodovia municipal (agora Avenida) Augusto Montenegro e seguindo para o distrito de Icoaraci, de onde parte, em seguida, retornando à Cidade Velha em percurso fluvial (no chamado Círio fluvial).

Assumindo a perspectiva apresentada por Maués (2012) como auxiliar em nossa compreensão, o Círio apresenta-se como:

(...)um conjunto de rituais que incluem várias "romarias" (pequenas procissões), a Trasladação, o Círio propriamente dito, a Festa de Arraial, as Novenas, as Missas, as manifestações paralelas, mas integradas a ele, como a Festa das Filhas da Chiquita, o Auto do Círio, a Feira de Brinquedos de Miriti, os fogos, a Procissão da Festa, o Recírio e muitas outras formas de celebração religiosa ou rituais paralelos. Como acontece em algumas festas religiosas católicas, o Círio se compõe de duas procissões principais: a primeira, a chamada Trasladação, é aquela que ocorre na noite anterior, que transporta a imagem de um lugar para outro: ela segue das imediações da Basílica de Nazaré, onde fica a maior parte do ano, para a Catedral, mais conhecida como Igreja da Sé. Por ser noturna, essa procissão é feita à luz de velas (círios), embora as luzes elétricas da cidade não se apaguem. No dia seguinte, pela manhã, é que se faz a procissão principal, o Círio propriamente dito (Maués, 2012: 164. Meus grifos).

O Círio é oportunidade de se renovar pedidos e pagar promessas, superando situações que se apresentam como limítrofes e que requisitam a tomada de medidas como a busca da cura através de engajamentos nos quais o corpo participa das dimensões do sagrado (Paes, 2012). Aí surgem os ex-votos, objetos sagrados que circulam pela paisagem da cidade, junto aos corpos e espelhos de corpos, antes doentes, agora sarados, mãos, pernas, cabeças de cera ou madeira, muletas, bengalas, entre outros pedidos e desejos urgentes.

No que se refere a estes artefatos, na percepção de Maria Augusta Machado da Silva (1981), museóloga, autora de obra considerada referencial sobre ex-votos e seus sentidos no Brasil, estes são produzidos como:

(Alves, I., 1980; Maués, 1995, 2009, 2012; Pantoja, 2006), identitárias, históricas e patrimoniais (Iphan, 2006; Coelho, 1998; Henrique, 2011) e midiáticas (Montarroyos, s.d.; Alves, R. 2012), entre tantos. 
(...) prática desobrigatória posterior à graça ou mercê alcançada, como testemunho público contemporâneo, não só da força milagreira da divindade (ou seus agentes), mas também da gratidão do milagrado. Tem, como componente subjacente, a divulgação vaidosa do mérito do agraciado que, entre tantos fiéis são atendidos, obteve uma graça especial da divindade (ou de seus agentes). O que dá mais ênfase a este aspecto de eleição é o fato de a maioria absoluta das graças alcançadas estar relacionada como problemas comuns a toda gente: risco de morte, doenças, perigos, dificuldades da vida etc. (Silva, 1981: 17. Meus grifos).

Neste "grande espelho" a que chamamos de religião, DaMatta (1986) nos aproxima da lógica da dádiva (Mauss, 2003) e de uma religiosidade brasileira de intermediação e circulação, que impõe fluidez e desafia fronteiras rígidas entre o sagrado e o profano:

As súplicas acompanhadas de objetos, na forma de promessas, ofertas e sacrifícios, são naturalmente mais fortes que um simples pedido verbal, pois que elas implicam um ato de cometimento muito mais denso e dramático, às vezes exigindo o gasto e parcelas de dinheiro que são críticas em termos da economia doméstica e pessoal do ofertante (DaMatta, 1986: 111. Meus grifos).

Os ex-votos são "artefatos-testemunhas", "artefatos-orações", "artefatosperformances", neles se encontram as dimensões "materiais" e "imateriais" da crença de forma dramática, inseridas na paisagem da devoção do Círio. O sentido de cada devoto (e ex-voto) é, ao mesmo tempo, único e coletivo, tanto expressa o conjunto dos problemas e das aflições que marcam a trajetória do devoto, quanto às questões comuns à experiência e sentidos referidos à coletividade dos paraenses e dos brasileiros.

Além disso, a promessa é um pacto que obriga os dois lados a alguma ação positiva no sentido de resolver o problema apresentado. Se eu, assim, peço uma graça e logo em seguida me sacrifico com a oferta de algo precioso para o santo (ou santa) de minha devoção, a lógica social faz com que ele (ou ela) também se obrigue a resolver meu problema, atendendo cortesamente a minha súplica (DaMatta, 1986: 111. Meus grifos).

Identificam-se na devoção elementos comuns à cultura nacional, tais como a religiosidade popular marcada por característica relação sagrado-profano, públicoprivado, junto ao culto dos santos, um misto de distância respeitosa e íntima familiaridade (Montes, 2012).

Como morador da cidade que se mobiliza na festa e desfile devoto que é a procissão, vou reencontrar os ex-votos em um espaço diferente: o Museu do Círio do Pará, pertencente ao Sistema Integrado de Museus e Memoriais (SIM/SECULT-PA). Destituído de sua "vida original" embarcam em outra jornada, agora apropriados como 
"patrimônio".

Enquanto técnico sou requisitado a registrá-los produzindo documentos, categorizá-los e dispô-los de forma a que "recuperem" sua capacidade comunicativa voltada para a educação patrimonial e cidadã. Porém, alguns destes “objetos”, e isto é constantemente discutido e comentado junto aos demais técnicos, coordenadores e diretores, demandam um contínuo esforço de "relacionar" (evitando o sentido de produzir ligações terminais e lineares) aos contextos etnográficos de sua origem.

O ponto de vista expresso é sempre da ação que supera o "apagamento" da memória, uma ação de "restauração-recuperação". O técnico no museu visto como alguém sempre pronto para lutar contra o "esquecimento". A passagem já plenamente moderna do "museu-memória" para o "museu-narrativa", do culto da "memória", acionada pelo mana do objeto, ao culto da "razão histórica" (Gonçalves, 2007; Demarchi, 2012), que requisita do objeto seu esvaziamento, em operação que nos aproxima do debate apresentado por Latour (2002) nos confrontos entre feito e fato, fetiche e anti-fetiche. Porém, como veremos neste artigo, termos como "esquecimento" ou "recuperação" não são adequados quando consideramos que não haveria perda, mas fluxos da matéria, processos nos quais podemos ou não enfatizar uma etapa da trajetória do ex-voto.

A primeira proposição que surge do esforço de pesquisa sobre os ex-votos é que estes consistem uma etapa de um processo ritual e performático que envolve o voto, sendo os ex-votos uma etapa de sua "biografia". Isto considerado, para melhor compreendê-los devemos pensar estes artefatos em conexão com sua paisagem e corporeidade.

\section{A paisagem devocional: efemeridade de uma paisagem em movimento}

Como parte e etapa de um processo, a circulação de votos e ex-votos se dá no espaço urbano de Belém, durante as procissões e festas devotas do Círio, no qual se destaca como "principal" a procissão do segundo domingo de outubro. A grande multidão que se reúne diante da Catedral da Sé para o início da caminhada que levará a Santa e seus fiéis até a Basílica de Nazaré, agora Santuário, no bairro de Nazaré, muda o "clima" da cidade. Podemos, assumindo esta direção, falar em uma "paisagem devocional" do Círio. Para tanto devemos pensar na própria categoria "paisagem" e em como ela instrumentaliza nossa compreensão sobre Círio e ex-votos. 
Assumo concepção em que corpo, performance e paisagem surgem como eixos contínuos e intercambiáveis de sentidos. Pensar corpo e memórias da cidade como perspectivas de ação ativa sobre o espaço, resistindo a considerar a cidade mero cenário no qual os sujeitos são inseridos no espaço urbano e percebidos como não contíguos a este e cujos termos principais ainda seriam a "passividade", "monotonia" e "cerceamento".

É diante desta tendência que se demonstra necessária a percepção de uma corpografia, termo apresentado por Jacques (2009), voltada para a devoção no Círio. Corpografias que impõem a consideração das diferentes memórias da cidade que se apresentam inscritas no próprio corpo, ao considerar que os registros de experiências corporais dão forma aos múltiplos esboços ao longo das histórias da cidade, portanto uma cartografia urbana deve lidar com a hipótese de que “(...) a experiência urbana fica inscrita, em diversas escalas de temporalidade, no próprio corpo daquele que a experimenta, e dessa forma também o define, mesmo que involuntariamente" (Jacques, 2009: 130). ${ }^{4}$

Ora, uma categoria da análise fenomenológica de Merleau-Ponty (2006) nos auxilia na quebra de paradigmas positivistas e na compreensão desta corpografia urbana, ao refletir sobre as categorias "espaço" e "mundo". Ao contrário da ciência moderna que resiste em ainda operar a separações duras entre objetivo e subjetivo, idealismo e empirismo, metafísica e positivismo, Merleau-Ponty (2006) propõe o rompimento com essas dicotomias na ciência, como forma de reaproximação entre o "sujeito" e o "objeto". Pois, o sujeito enquanto pesquisador tem que se voltar para ele mesmo, que seria o retorno às coisas mesmas, e encarar essas coisas como realmente elas são.

Neste sentido, o mundo “(...) não é aquilo que penso, mas aquilo que eu vivo; eu estou aberto ao mundo, comunico-me indubitavelmente com ele, mas não o possuo, ele é inesgotável" (Merleau-Ponty, 2006: 14. Meus grifos), situação que nega o espaço como homogêneo, e que reclama nossas singularidades corporais, nossa intencionalidade como habitantes de um meio familiar.

Passível também de nos servir como ponto de apoio e convergência das

\footnotetext{
${ }^{4}$ De forma a visualizar a possibilidade desta corpografia, o relato de Saré (2005) sobre técnicas do corpo, memória, movimento processional, seus caminhos na cidade e a corda do Círio de Nossa Senhora de Nazaré se entrelaçam e acionam mutuamente.
} 
discussões atuais sobre o tema, Silveira (2009: 71-72) em seu debate propõe que se conceba a paisagem como "entidade fenomênica" e "múltipla (plural)", “biogeocósmica”. Assim, afirma entender: “(...)paisagens como manifestações culturais. Ou seja, toda e qualquer paisagem mediante ato cognitivo de interpretação, intimamente associado à percepção e à representação emerge como fenômeno cultural experenciado em um contexto específico" (Silveira, 2009: 72. Meu grifo).

As dimensões fenomênicas da paisagem permitem afirmar que imagens/representações antecedem a paisagem? São arbitrárias, mera especulação? Não, devemos fugir da dicotomia excludente, não só como método, mas como produto deste método, pois constatamos que se tratam de espaços praticados/vividos.

O espaço/paisagem é experimentado/experenciado e, como considero propõe Silveira (2009), constituído desconstruindo as fronteiras interno/externo, interior/exterior, espírito/matéria, assim, “(...)[a] paisagem enquanto tal é passível de ser interpretada, encerrando assim, uma hermenêutica em si mesma: ela é ao mesmo tempo a escrita e a leitura porque a ação humana que engendra marcas não se dá sem a interpretação" (Silveira, 2009: 73. Meus grifos).

O homem "representa" e "é" paisagem. Tanto modifica como é modificado no ato criativo e fluído das paisagens. Sendo unidade da paisagem para outros interpretes, assim como interprete ele próprio, projeta versões e imagens sobre espaço e tempo, que longe de se apresentarem como "apenas" representações são atos plenos de configuração das matérias da paisagem, pois demandam continuamente o fluxo dos participantes em "inter-ação". Para nos aproximarmos da paisagem devocional do Círio, registro, produção ou seleção de imagens não é somente instrumentalização, mas atos de reflexão contínuos às demais formas textuais.

Ainda neste raciocínio, a concepção de paisagem (landscape) apresentada por Tim Ingold (2000) igualmente rejeita a divisão entre mundo "interior" (subjetividade pura) e mundo "exterior" (objetividade pura), assim:

(...) neither is the landscape identical to nature, nor is it on the side of humanity against nature. As the familiar domain of our dwelling, it is with us, not against us, but it is no less real for that. And through living in it, the landscape becomes a part of us, just as we are a part of it. Moreover, what goes for its human component goes for other components as well. In a world construed as nature, every object is a selfcontained entity, interacting with others through some kind of external contact. But in a landscape, each component enfolds within its essence the totality of its relations with each and every other (Ingold, 2000: 191. Grifos do original). 
Não se confundindo nem com "terra", "ambiente" ou "espaço" (Ingold, 2000), a paisagem é o mundo como ele é conhecido por aqueles que habitam nele, que habitam seus lugares e empreendem jornadas ao longo dos múltiplos caminhos de interligação, conexão, não uma imagem na imaginação, pesquisada pelo "olho da mente"; nem o substrato "alienígena" e sem forma, aguardando a imposição da ordem humana

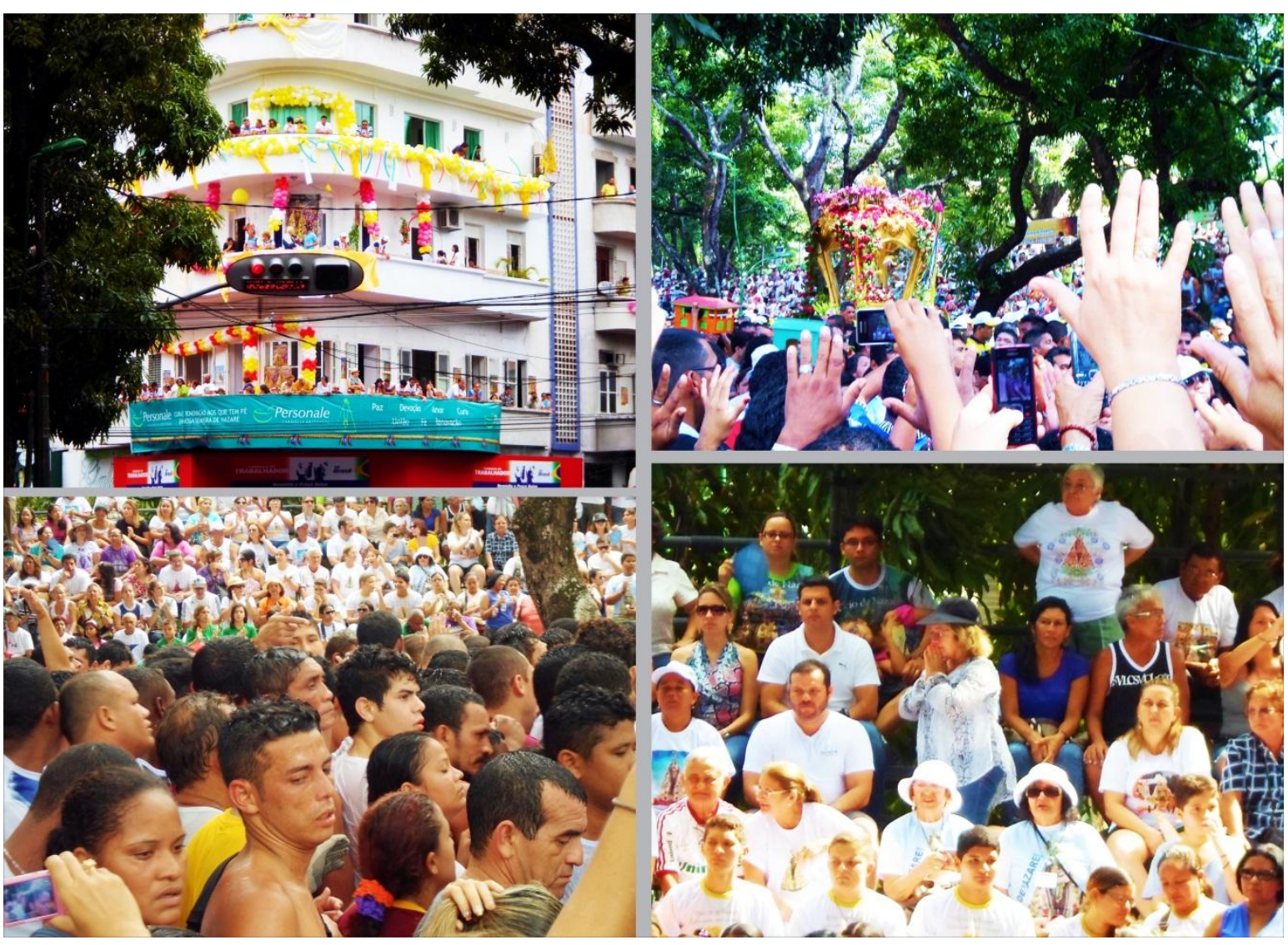

Imagem $1^{5}$ - A paisagem devocional no Círio de Nazaré, @ Anselmo Paes.

Uma paisagem devocional aprecia e amplia a percepção da paisagem cultural sob prisma fenomênico, considerando a paisagem fluída e efêmera do movimento processional e devoto que constrói e transforma o espaço, o sacraliza, o desacraliza, impõe tempos diversos, sobrepõem vivências espaciais, temporais e imagéticas. Mundo

\footnotetext{
${ }^{5} \mathrm{O}$ conjunto apresenta no sentido horário (superior esquerda), um marco da paisagem urbana, o Edifício Manoel Pinto da Silva em uma das muitas formas de participação na procissão, em espaço privilegiado na esquina da Avenida Presidente Vargas e Nazaré, após o "túnel de mangueiras" que ameniza o calor do trajeto na Praça da República. A aproximação da Santa, quando mãos se erguem para agradecer, receber e tocar a "santinha". Agora também se erguem em busca da captura de sua imagem através de telefones celulares. A participação nas arquibancadas em busca de "ver a passagem" da Santa. A proximidade da imagem mobiliza a fiel, suas mãos são postas próximas ao rosto, olhos fechados ou fixos na imagem sagrada em prece que sobrepõe o íntimo e o público. $\mathrm{O}$ ato performático de "ir na corda”, o qual faz encontrar a dor e prazer dos corpos da paisagem devocional, performance que compõe uma ação no campo da prece e oração (Círio de Nazaré-PA em 14/outubro/2012).
} 
praticado, no qual cosmologias e experiências do sagrado se arquitetam sob a marca dos corpos, assim, produzindo corpografias. Memórias dos corpos que se movimentam no cumprimento do voto e em performance realizam o ex-voto, o publicizando, ao pagar a promessa, apresentando o corpo curado para satisfação de homens e divindade, em uma relação que é literalmente "visceral" como é visto na corda (artefato-ação), referência na caminhada atualizadora e memórias do caminho.

\section{O corpo engajado em voto e ex-voto: instrumento e reflexão}

A corda dos promesseiros, um dos espaços/artefatos performáticos que compõem a paisagem do Círio, é uma forma de ofertar o próprio corpo à divindade. As pessoas experimentam a paisagem e as performatizam, suas crenças se expressam e são compartilhadas em seus corpos, em uma "razão" que é também "corpo".

Nosso conhecimento, portanto, não é exclusivamente racional, pois tem início com as sensações corporais, às quais confrontadas aos outros (outros corpos, outras histórias, outros "eus") imprimem sua própria experiência ao mundo, assim modulam, limitam-se mutuamente. O corpo é a primeira instância de conhecimento que informa dados que serão organizados pelos esquemas mentais e culturais.

Por meio das sensações o corpo se enraíza no mundo e essas impressões consistirão em sentidos e significados construídos pela experiência, que também é uma experiência do outro. David Le Breton (2007) afirma a necessidade de marcar que a existência é corporal. Nesta existência, o ator abraça fisicamente o mundo, apoderandose dele. Uma sociologia e antropologia do corpo (ou que "dá confiança" ao corpo) compartilham, assim, da concepção fenomenológica para a qual o corpo é um “(...)veículo do ser no mundo, e ter um corpo é, para um ser vivo, juntar-se a um meio definido, confundir-se com certos projetos e empenhar-se continuamente neles" (Merleau-Ponty, 2006: 122).

David Morgan (2010a), contribuindo com a linha de reflexão apresentada, quer enfatizar perspectiva de trabalhar crença e materialidade da religião, considerando que a religião não consiste exclusivamente de razão e abstração, porém nas instâncias da vida material que desenha o mundo espiritual, pois: “(...)[t] he transcendence does not come to them as pure light or sublime sensations in most cases, but in the odor of musky shrines or moldering robes or the pantry where they pray" (Morgan, 2010a: 8). Daí o 
corpo e a corporeidade como instrumentos para o estudo do que chama de "cultura material religiosa":

Material culture consists of the things, the practices of using things, and the forms directing their uses on which we build and maintain the worlds about us, and thereby encounter and value ourselves and others. The three dimensions of material culture are things, uses, and paradigms. Material culture is not just objects, not just architectural foundations or jewery or paintings because, as we saw above, things are more than things. (Morgan, 2010b: 73. Meus grifos).

Coisas são mais que coisas. A crença não está na "cabeça" das pessoas, mas vestida nelas, elas a habitam, a executam e a expressam, reconstituem cotidianamente através de performances e rituais.

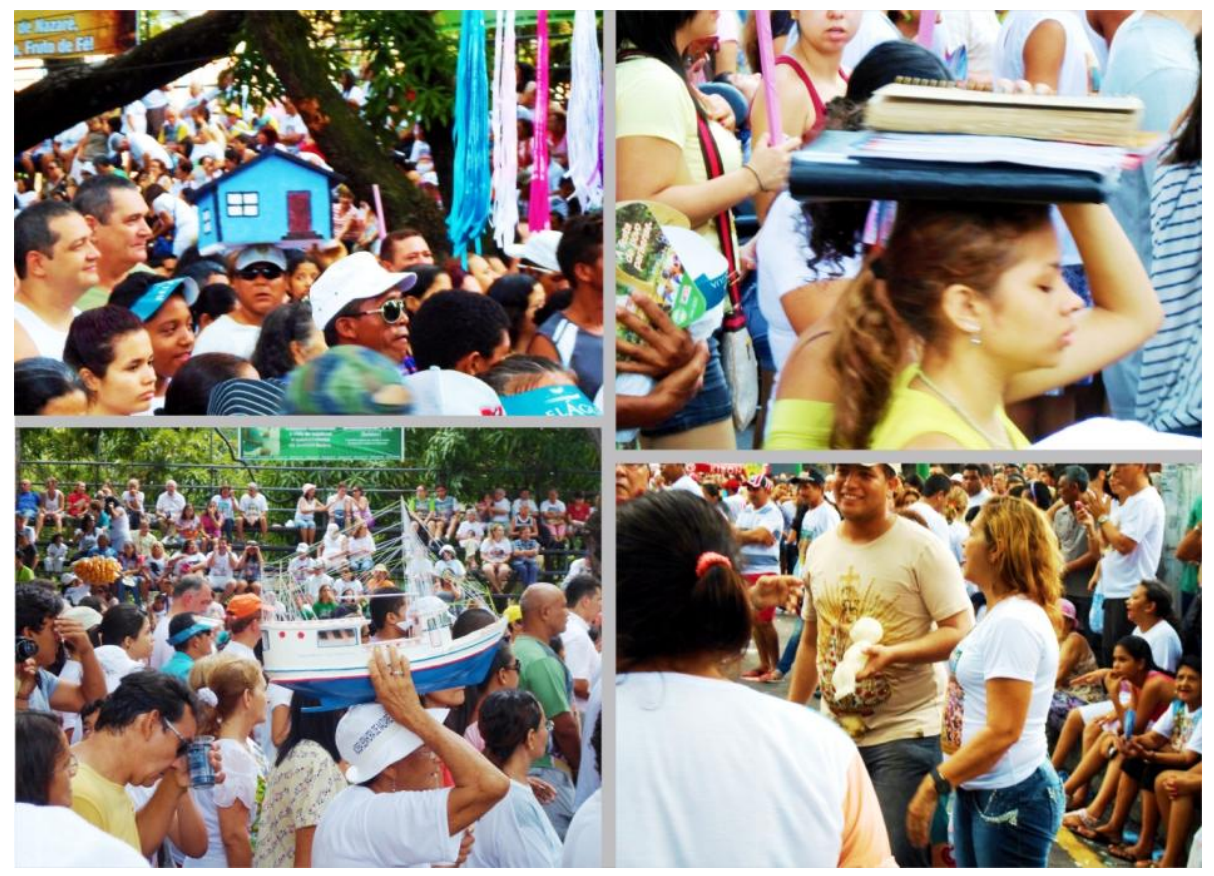

Imagem $2^{6}$ - O corpo engajado no Círio, @ Anselmo Paes.

Na procissão veem-se os promesseiros carregando ex-votos representando casas, barcos, animais, materiais de construção, os corpos e partes do corpo (esculpidas em

\footnotetext{
${ }^{6} \mathrm{O}$ conjunto apresenta no sentido horário (superior esquerda), uma casa de isopor, na qual a precariedade relativa do material (frágil, leve e acessível), não impõe limites à criatividade, cujas formas e cores visam expor e visibilizar o pagamento da promessa no "carnaval devoto", quando suspenso na cabeça do devoto, acima do choque dos corpos e, assim, visível a todos. Apostilas e livros, que equilibrados sobre a cabeça de devota durante a procissão do Círio, requerem disciplina e postura para resistir ao trajeto, o que se anuncia na expressão compenetrada da promesseira. $\mathrm{O}$ pequeno boneco de cera apresentado manifesta a oportunidade de ver e ser visto, publicizar a devoção e seu pagamento nos trajetos da cidade, este como é chamado frequentemente é um "rio de gente" expressão que marca a presença do rio no discurso e no imaginário da procissão amazônica (Círio de Nazaré-PA em 14/outubro/2012).
} 
cera, miriti, gesso ou em madeira) mostrando ao mesmo tempo os males e as alternativas encontradas para a resolução de seus problemas.

A representação imagética mais significativa relacionada à Nossa Senhora de Nazaré é a de "mãe", expressa como proximidade, relação de proteção e cuidados, assim ao apresentar e depositar o ex-voto o devoto está colocando-se materialmente sob a guarda da "mãezinha", o artefato não é mera representação e sim, manifestação material do devoto e sua história. As lógicas suscitadas são a da simpatia, do contato e do duplo (Frazer, 1982).

Roupas vestem imagens de cera, mantos são doados à Virgem de Nazaré, a camisa do time de futebol preferido, o uniforme da profissão almejada, a roupa usada em momento de perigo ou dificuldade, o traje do anjo, as mortalhas, corroborando com a análise de corpos e artefatos. Peter Stallybrass (2008) ao relatar sobre a vida social das coisas, expõe sobre o quanto a roupa tem a capacidade de manter a memória do ausente, do corpo dos que já foram.

A roupa nos recebe: nosso cheiro, nosso suor, até mesmo nossa forma, é por isso que o momento ritual de esvaziar armários, gavetas parece tão duro, confrontar-se nesse momento de crise, da morte, da partida, com o terror dos "traços materiais", capazes de usurpar o lugar de seus antigos portadores, junto aos ex-votos registrados no Círio as roupas estão presentes como um dos objetos mais presentes dentre as doações. Artefatos que recebem e moldam corpos, que constroem "eus", tanto moeda como meio de incorporação, as roupas se moldam e amoldam nossa forma humana, nosso corpo, marca e memória, de maneira especial desafiam os limites entre objeto e corpo.

Corpo e santidade são esferas relacionadas e importantes no estabelecimento da religiosidade na América portuguesa. O uso do corpo como instrumento de resistência e salvaguarda da fé. A imitatio Christi ligada à encarnação e martírio tornava as instâncias corporais como o palco da comunhão com o sagrado. Neste sentido tomar a doença como sinal de eleição, apropriar-se dela e torná-la como oportunidade de purificação da alma (Oliveira, 2011).

Portanto, ao acompanhar o Círio a pé, ou mais espetacularmente, "na corda", mesmo que apenas por um trecho do longo trajeto, mas também através da performance de carregar os ex-votos durante sua caminhada para então depositá-lo em um dos carros de milagres ou na própria Igreja, nos apresenta a centralidade das instâncias corporais no Círio, cujo jejum se encerra ao final da procissão no farto "almoço do Círio". 
Retornando à Morgan (2010b), seguindo as proposições apresentadas buscamos constatar sobre a ampliação de fronteiras de estudos como propõe, quando se considera que a cultura material revela sua potência quando se percebe o quanto:

Their edges fade into the systems of value we rely on to recognize and deploy them. Their boundaries fade as they are deployed in practices, merging into bodies and spaces in the medium of feeling. Things are present or absent according to the proposes and needs that drives ours activities. But things are also recalcitrant, resist forces that challenge the schemata or paradigms of culture, the expectations or dispositions that shape human perception (Morgan, 2010b: 73. Meus grifos).

Corpo, mente e coisas não são tão distintas como certas análises clássicas frequentemente apresentam, assim, uma "antropologia do objeto" deve avançar considerando através de várias aproximações e métodos que, reconhecendo o corpo e o seu envolvimento nos espaços e coisas como integralmente envolvido na produção de experiência, nós somos instigados a reformular o entendimento da própria matéria.

\section{O "objeto" vazado: fluxos da matéria}

O ex-voto inicialmente registrado como costume das elites, ao se popularizar, fica a cargo de artesãos e artífices, em geral anônimos, quando posteriormente diversificam a sua forma. Depositados nos santuários, nas "salas de milagres", em razão dos materiais perecíveis e frágeis empregados (como a cera, o papel e o próprio miriti ${ }^{7}$ ) e de furtos (quando se trata de metais nobres), muitos se perderam com o tempo, daí o trabalho de coleta, catalogação e pesquisa realizado, por exemplo, pelo Museu do Círio em sua preservação.

O milagre ou a graça, que se paga ou deseja pagar, é como se chama o efeito que escapa à razão humana e que se acredita ser causado por intervenção divina. $\mathrm{O}$ ex-voto é testemunho ${ }^{8}$ do milagre, oferecido ao santuário como prova material da gratidão. São registros do episódio ou objetos feitos em cera, gesso, madeira, osso, e mesmo ouro, prata, marfim, materializando-os como oferta.

\footnotetext{
7 Matéria-prima que consiste do pecíolo ou "bucha" da palmeira miriti ou buriti-do-brejo (mauritia flexuosa).

${ }^{8}$ Um dos olhares relevantes na academia brasileira volta-se para os ex-votos principalmente observandoos nos espaços museais e nas chamadas "salas de milagres" (Oliveira, J., 2013), sob ênfase no objeto como mediador de comunicação popular, em perspectivas semiológicas e museológicas, que tem orientado algumas abordagens.
} 
Uma aproximação "biográfica” (Kapytoff, 2011) tem sido utilizada para, construindo a carreira do artefato, poder pensar-se estes artefatos em processo, verificando-se as mudanças de status que compõe a "biografia social" do mesmo, demonstrando que enquanto entidades culturalmente construídas são permanentemente classificadas e reclassificadas.

Tomando, por exemplo, um livro utilizado em preparação para prestação de concurso público que se encontra no acervo do Museu do Círio de Belém (PA). Durante a jornada de um ex-voto devemos sempre considerar a multiplicidade de artefatos e ações que podem ser incluída nos processos de produção simbólica de votos e ex-votos. O livro, um manual de direito, foi utilizado durante etapa da biografia de seu portador e o acompanhou diariamente em seus esforços, marcas são impressas nele (o artefato): como assinatura do nome do proprietário, textos no quais agradece a aprovação, nas marcas, sublinhados e comentários escritos em margens das páginas e junto aos trechos mais importantes, antes ele esteve em uma livraria em uma secção especializada.

Talvez não considerasse seu potencial como parte do universo sagrado, porém seu proprietário, quando alcançar o intento almejado (compartilhado por grande parte da população) de ingressar nos quadros do serviço público, ele participará de relação com a Santa, ao acompanhar seu trajeto (de dia ou de noite), talvez sobre a cabeça do devoto. Pode ser colocado diretamente no "carro dos milagres", ou ainda levado até a Basílica Santuário para, então, estar exposto em seu altar. Em uma biografia possível este ainda poderá ou ser incluído no espaço memorial do Círio ("Memória de Nazaré”, criado pela Diretoria da Festa de Nazaré, ou do "Museu do Círio", administrado pelo SIM/SECULT-PA) ou doado, novamente alienado ou descartado ${ }^{10}$.

Neste trajeto múltiplo ele passa de mercadoria para artefato único e sagrado, no âmbito da promessa, ou seja, transita entre esferas de circulação e valores diferentes (com algumas lógicas aproximadas), de coisa alienável e passível de receber um "preço", para inalienável, estando fora do mercado mundano e dentro do mercado de trocas e dádivas dos santos. Adentrando as paredes de um memorial ou museu como patrimônio cultural material e/ou imaterial (adentrando outra esfera do sagrado) ${ }^{11}$, ou

\footnotetext{
${ }^{9}$ Como se denomina os atualmente treze carros que fazem parte do cortejo do Círio e que recebem durante seu trajeto a doação de ex-votos, contando com o acompanhamento de voluntários com frequência estudantes.

${ }^{10}$ Até o presente momento não encontro registros sobre a existência de "sala de milagres" junto à Basílica de Nazaré. A hipótese é de que suas funções, em parte, são supridas na performance da procissão e junto ao "carro dos milagres".

${ }^{11}$ Ao apresentar uma "aura", esta considerada assim definida como “(...)aparição única de algo distante,
} 
ainda, como já indicado, retornar ao mercado "mundano" e novamente receber preço.

Ora, Kapytoff (2011) em sua análise nos propõe atenção ao fato de que, assim como uma pessoa, as coisas têm muitos movimentos possíveis e muitas biografias possíveis (psicológica, profissional, política, familiar e econômica) nos quais se selecionam certos aspectos da biografia e descartam outro. Acatando a variabilidade destas biografias, desvelam-se as múltiplas camadas da participação dos artefatos em várias das instâncias da vida cultural.

Já Ingold (2012), não considera este percurso suficiente e, por sua vez, busca afastar-se tanto das abordagens centradas nas pessoas e na subjetividade, quanto das abordagens centradas nos "objetos", exatamente repensando-os como "coisas". O processo que busca é inverso ao que aponta como representativo das abordagens sobre "objetos", concentrados em aspectos "funcionais", que sustenta a seu ver uma inadequada dicotomia entre as pessoas, estes objetos e o mundo. Busca Ingold (2012) concepção ontológica enfatiza os processos de formação em oposição do objeto (produto final, fato consumado), logo o mundo é composto por coisas (processo).

Esta abordagem sobre as coisas está atenta para os processos de formação, aos fluxos e suas transformações. Coisas têm vida, percepção que é trabalhada enquanto “(...)capacidade geradora do campo englobante de relações dentro do qual as formas surgem e são mantidas no lugar.” (Ingold, 2012: 27). Seu alerta é quanto à redução das "coisas" aos "objetos" e de sua correspondente retirada dos processos vitais, ou seja, não a materialidade, mas o fluxo de materiais. Seguir estes fluxos, trilhar os caminhos geradores, nos quais uma coisa é uma concentração destes fluxos, de linhas em uma malha que não conecta, mas aproxima-se e encontra outros fluxos vitais, estes emaranhados são, assim, momentos em fluxos.

Propondo a compreensão do mundo e sua dinâmica, as "coisas" estão em fluxo, enquanto os "objetos" são autocontidos; o primeiro refere-se aos processos e o segundo oferece um resultado final; um apresenta-se como o encontro e um emaranhado de linhas de forças, o outro como produto do isolamento dos fluxos vitais; o primeiro é "vida", o outro é "morte".

Em contraste com os "objetos", as "coisas" não são uma "(...)entidade fechada para o exterior, que se situa no e contra o mundo, mas de um nó cujos fios constituintes, longe de estarem neles contidos, deixam rastros e são capturados por outros fios noutros por mais próximo que esteja” por Walter Benjamim (2012: 14). 
nós" (Ingold, 2012: 29) e é esta perspectiva que instrui o esforço de compreensão, do qual surge o método: seguir os processos (fluxos)

Ao evitar a distinção entre coisas e pessoas como fundamento analítico, a concepção de que ao invés de atentarmos para a "matéria" devemos pensar em um "mundo de materiais", assim sugere que trazer objetos (de volta) à vida, indica que inserindo-nos em um mundo em formação, mundo animado em constante fluxo gerativo, considerando que "(...)as coisas vazam sempre transbordando pelas superfícies que se formam temporariamente em torno delas" (Ingold, 2012: 29).

No atual momento de reflexão sobre o campo dos artefatos o olhar dos autores já apresentados pretende quebrar as distinções duras entre campos da objetividade e da subjetividade, nos oferecendo a perspectiva de que as coisas devem ser percebidas como compondo uma assemblage $^{12}$ (agenciamentos) (Deleuze; Gattari, 2011: 18).

Considerando a proposição de uma assemblage, o humano e o não-humano não se encontram separados. As coisas estão dobradas sobre si, em um "enxame" e "nós" de vitalidades, como indica Ingold (2012). Esta agência, remetendo e ampliando a tão debatida perspectiva apresentada por Gell (1998), não está localizada nos objetos ou no corpo humano por si só. Em vez disso, a agência é sempre confederada, múltipla, distribuídas em assemblages.

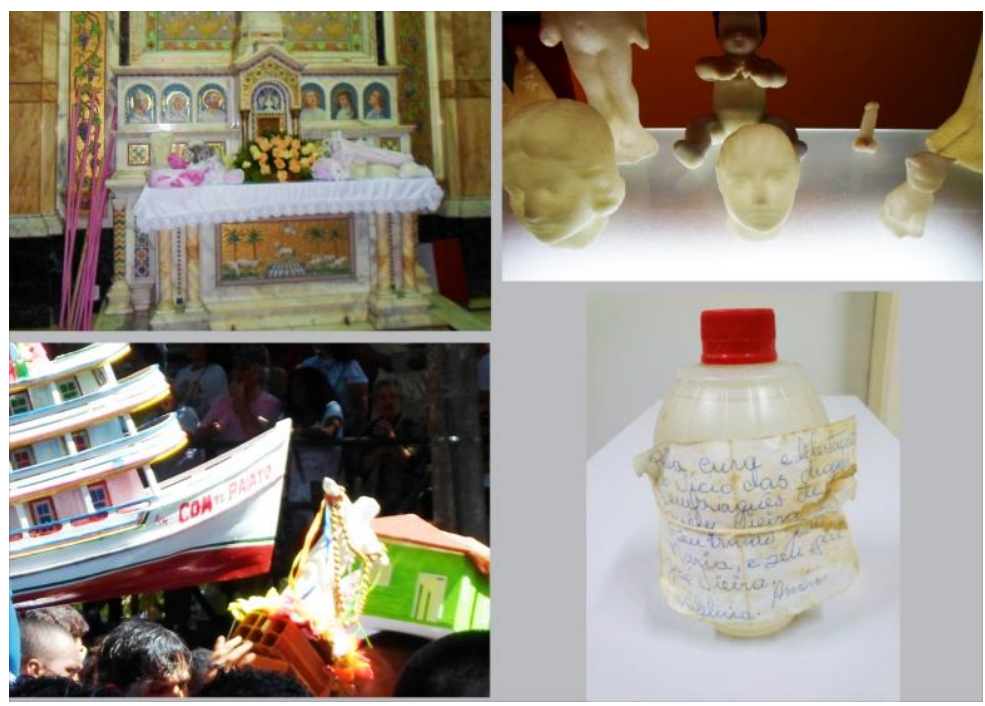

Imagem $3^{13}$ - Fluxos e encontros, @ Anselmo Paes.

\footnotetext{
${ }^{12}$ Apropriando-me desta ideia de forma livre, apresentada por Deleuze e Gattari (2012), mantenho o termo em sua língua nativa para expressar e reforçar sua concepção enquanto categoria analítica. $\mathrm{Na}$ tradução utilizada, o termo apresenta-se por "agenciamentos", a manutenção do termo estrangeiro também permite que o distinga da proposição de "agência" em Gell (1998).

${ }^{13} \mathrm{O}$ conjunto apresenta no sentido horário (parte superior esquerda), um altar lateral da Basílica
} 
Por isso me aproximo da imagem instrumental da assemblage, número de coisas ou partes de coisas, linhas e velocidades entrelaçadas em um único contexto, tessitura (Deleuze; Gattari, 2011: 22) que pode trazer um número de efeitos: sejam estéticos, produtivos, econômicos, etc., assim para alcançar as coisas, como os ex-votos em sua potencialidade, deve-se acessar essa assemblage a partir de ângulos e linhas diversas considerando nossa incapacidade de impor fronteiras, limites e distinções. Um ex-voto pode, como temos visto, participar de uma assemblage de vitalidades, pois seu status instrumental não o esgota ou o previne de conter ou participar de outras assemblages.

\section{Tecendo aproximações: corpos, paisagens e coisas}

A concepção do "objeto" ensimesmado é substituída por tessitura teórica na qual a fenomenologia dos artefatos culturais se destaca. Morgan (2010a, 2010b) propõe compreensão da cultural material sob este aspecto: performance, corpo, espaço e coisa, a materialidade da fé se apresenta assim. Cascudo (2011) ao tratar da religião popular nos fala da oração em forma de pedrinhas depositadas em cruzeiro, assim como ao lidar com um objeto dos mais ordinários, a rede, nos fala de sua cosmologia, ou seja, em certa leitura seu trabalho, considerado clássico, já desafia as fronteiras da materialidade e subjetividade enquanto dimensões estanques de aspectos especializados na aproximação com a cultura (Cascudo, 2003).

A reflexão sobre as paisagens devocionais que se propõe necessária para o entendimento do processo de realização do voto e produção do ex-voto, não é mero cenário, mas investindo na perspectiva de Kapytoff (2011) é parte de uma biografia social que, por sua vez é reveladora dos fluxos da matéria e nós vitais que instituem, não simples agência, seja nos "objetos" ou nos "sujeitos", mas no mundo.

Os desafios, apresentado por Ingold (2012), que este entendimento dos entrelaçamentos da materialidade traz é considerável. Significa tomar mais seriamente as propriedades não só físicas, mas políticas, estéticas, ritualísticas, comunicacionais

Santuário no qual se vê o acúmulo de ex-votos nos altares da Basílica Santuário indicando o prestígio da Santa, construindo um discurso visual de sua potência, aproximado ao das "salas de milagres" e ex-votos no Museu do Círio, coletados ou doados ao espaço "sacralizado" do museu quando entregues à lógica museológica do patrimônio cultural. Também um ex-voto, compósito, no qual temos a garrafa conhecida popularmente como "buchudinha", repleta de cachaça, a qual fixado com cordão de algodão, soma-se a bilhete, no qual está inscrito: "pela cura e libertação do vício das drogas e embriaguez de Suely Vieira e o seu irmão João Maria, e o seu pai José Vieira. Aleluia. Amém”. No encontro de votos e ex-votos, as coisas formadas por outras coisas, suscitando outros conjuntos, cada uma contêm seu próprio fluxo existencial e agenciamento mútuo (Círio de Nazaré-PA e Museu do Círio em 14/outubro/2012 e 17/maio/2013). 
das coisas, admitindo abrir mão de fronteiras impostas e considerar os artefatos como potencialmente indefinidos em um fluxo de relações contínuas em firme fluxo de expansão. Como proposta a perspectiva de uma assemblage de vitalidades que são os ex-votos, múltiplos em suas variedades, materiais ou performances, nos permite apenas certas aproximações e abduções da experiência, para cada oportunidade expressar um ângulo de sua compreensão e vitalidades.

No âmbito do catolicismo devocional os ex-votos são artefatos que expressam relação de agradecimento ou pagamento de graça pedida à divindade e seus agentes, santos ou santas de devoção, apresentando-se sob a lógica da dádiva (Alves, 1993). Ora, basicamente qualquer artefato pode ser transferido à esfera do ex-voto. Não são exvotos, tornam-se ex-votos. Ao refletir sobre os ex-votos, refletimos sobre os votos, ações que vinculam, transformam e acionam corpo e alma do devoto, modificam e constroem paisagens, produzindo um imaginário, materializando a memória.

Os variados votos nos apresentam quais são as situações limite da vida dos brasileiros: são casas (ou partes destas, como tijolos) (que denotam a necessidade de moradia), livros, apostilas, monografias (que denunciam as dificuldades em ingressar no ensino superior brasileiro), barcos, ônibus, caminhões, taxis e outros veículos (instrumentos de trabalho e busca de autonomia financeira), partes de corpos representados em parafina, muletas, próteses, bonecas, peças de vestuário (o corpo, primeiro instrumento do homem), que traduzem o desejo de saúde, bem nem sempre disponível a todas as classes sociais, igualmente como, em uma tipologia sempre em crescimento, cruzes, mantos decorados, terços, fitas, pedras, bilhas de água em cerâmica, que conformam e conformam-se ao corpo no lento movimento e tempo da procissão.

Ao falar de ex-voto estamos falando de relações, de memórias, de escolhas, de ações, de um processo ritual e performático de transformação, ou seja, estamos mergulhando em um fluxo de vitalidades que aproxima em tessitura homens e artefatos, corpos e lugares, memórias. O ex-voto, enfim concluímos, de fato não pode ser visto como um mero "objeto".

\section{Referências}

ALVES, Isidoro. O carnaval devoto: um estudo sobre a festa de Nazaré, em Belém. Petrópolis: Editora Vozes, 1980.

Promessa é divida...Valor, tempo e intercambio ritual em sistemas tradicionais na 
Amazônia. Tese de doutorado. Rio de Janeiro: Museu Nacional, 1993.

ALVES, Regina. O manto, a mitra e o microfone: a midiatização do Círio de Nazaré em Belém do Pará. Tese de doutorado. Belém: UFPA, 2012.

ARAÚJO, Alceu Maynard. Cultura popular brasileira. $2^{\text {a }}$ Ed. São Paulo: Martins Fontes, 2007.

BENJAMIM, Walter. "A obra de arte na era de sua reprodutibilidade técnica". In: et al. Benjamim e a obra de arte: técnica, imagem, percepção. Rio de Janeiro: Contraponto.p. 9-40. 2012.

CASCUDO, Luís. "Promessa (verbete)". In: Dicionário de folclore brasileiro. 12a Ed. São Paulo: Global. p. 582-583. 2012.

. Rede de dormir: uma pesquisa etnográfica. $2^{\mathrm{a}}$ Ed. São Paulo: Global, 2003.

. Religião no povo. $2^{\mathrm{a}}$ Ed. São Paulo: Global, 2011.

COELHO, Geraldo Mártires. Uma crônica do maravilhoso: legenda, tempo e memória no culto da Virgem de Nazaré. Belém: Imprensa Oficial do Estado, 1998.

DAMATTA, Roberto. "Os caminhos para Deus". In: O que faz o brasil, Brasil? Rio de Janeiro: Rocco, p. 109-118. 1986.

DELEUZE, G.; GUATTARI, F. Mil plâtos: capitalismo e esquizofrenia 2. V.1. São Paulo: Ed. 34, 1995.

DEMARCHI, Andre. "Os museus e seus fetiches". Revista eletrônica do programa de pósgraduação em museologia e patrimônio - PPG-PMUS Unirio/Mast, n. 1, v. 5, 2012: 87-102. ESCARDÓ, Zenia Yébenes. "El exvoto da que pensar. Homenaje a Alfredo Vilchis". Jornadas de antropologia visual. Disponível em: http://www.antropologiavisual.com.mx/es/homenajes-yretrospectivas/134-la-revolucion-imaginada.html?start=3. Acesso em 30/04/2013.

FRAZER, James. O ramo de ouro. Versão ilustrada. Rio de Janeiro: Editora Guanabara, 1982.

GELL, Alfred. Art and agency. Oxford: Clarendon, 1998.

GONÇALVES, José Reginaldo. Antropologia dos objetos: coleções, museus e patrimônio. Rio de Janeiro: IPHAN/DEMU, 2007.

HENRIQUE, Marcio Couto. "Do ponto de vista do pesquisador: o processo de registro do Círio de Nazaré como patrimonio cultural brasileiro”. Amazônica, n.3, v. 2. p: 324-346. 2011.

IPHAN, Instituto do Patrimônio Histórico e Artístico Nacional. Círio de Nazaré (elaboração do texto: Márcio Couto Henrique; Maria Dorotéia de Lima; Raymundo Heraldo Maués). Rio de Janeiro: IPHAN, 2006.

INGOLD, Tim. "The temporality of the landscape". In: . The perception of the environment: essays on livelihood, dwelling and skill. London: Routledge, p. 189-208. 2000.

. "Trazendo as coisas de volta à vida: emaranhados criativos num mundo de materiais". Horizontes antropológicos, Porto Alegre, ano 18, n. 37, jan./jun., p. 25-44. 2012. 
JACQUES, Paola. "Corpografias urbanas: a memória da cidade no corpo". In: VELLOSO, Monica Pimenta et al. (Orgs.) Corpo: identidades, memórias e subjetividades. Rio de Janeiro: Mauad X. p. 129-139. 2009.

KAPYTOFF, Igor. "The cultural biography of things: commoditization as process". In: APPADURAI, Arjun (Ed.). The social life of things: commodities in cultural perspective. $9^{\mathrm{a}} \mathrm{Ed}$. New York: Cambridge University Print. p. 64-91, 2011.

LATOUR, Bruno. Reflexão sobre o culto moderno dos deuses fe(i)tiches. Bauru: EDUSC, 2002.

LÉVI-STRAUSS, Claude. Totemismo hoje. São Paulo: Abril Cultural, 1980.

LE BRETON, David. A sociologia do corpo. $2^{\text {a }}$ Ed. Petrópolis: Vozes, 2007.

MAUÉS, Raymundo Heraldo. O homem que achou a santa: Plácido José de Souza e a devoção à Virgem de Nazaré. Belém: Basílica Santuário de Nazaré, Padres Barnabitas, Arquidiocese de Belém, Casa de Plácido, 2009.

. Padres, pajés, santos e festas: catolicismo popular e controle eclesiástico. Um estudo antropológico numa área do interior da Amazônia. Belém: Cejup, 1995.

. "Tradição, história, simbolismos, reciprocidade, identidade: o Círio de Nazaré em Belém do Pará". Revista de teologia e ciências da religião da UNICAP, n. 9, 2010: 163-183. Disponível em: http://www.unicap.br/revistas/teologia/arquivo/teologia\%202010\%202.pdf. Acesso em 12/07/2012.

MAUSS, Marcel. "Ensaio sobre a dádiva: forma e razão da troca nas sociedades arcaicas". In: . Sociologia e antropologia. São Paulo: Cosac \& Naify, p. 185-314. 2003.

MERLEAU-PONTY, Maurice. Fenomenologia da percepção. $3^{\text {a }}$ Ed. São Paulo: Martins Fontes, 2006.

MONTARROYOS, Heraldo. Festas profanas e alegrias ruidosas (A imprensa no Círio). Belém: Falângola Editora, s.d.

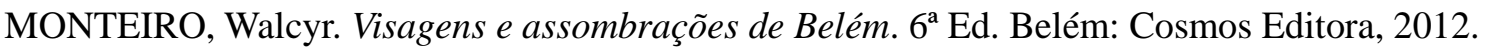

MONTES, Maria Lucia. As figuras do sagrado: entre o público e o privado na religiosidade brasileira. São Paulo: Claro Enigma, 2012.

MOREIRA, Eidorfe. Visão geo-social do Círio. Belém: Imprensa Universitária, 1971.

MORGAN, David. "Introduction: the matter of belief". In: culture. The matter of belief. New York: Routledge, p. 1-17. $\overline{2010 \mathrm{a} .}$

(Ed.). Religion and material "Materiality, social analysis, and the study of religions". In:

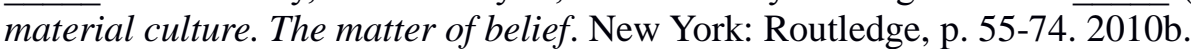

OLIVEIRA, Anderson José de. "Corpo e santidade na América Portuguesa". In: DEL PRIORE, Mary; AMANTINO, Marcia. História do corpo no Brasil. São Paulo: Editora UNESP, p. 45-68. 2011. 
OLIVEIRA, José Cláudio. "Semiologia dos ex-votos na Bahia: arte, simbolismo e comunicação religiosa". Revista internacional de folkcomunicação, v. 5, n. 9, 2007. Disponível em: http://www.revistas.uepg.br/index.php?journal=folkcom\&page=article\&op=view\&path\%5B\%5 $\mathrm{D}=560$ \&path\%5B\%5D=395. Acesso em 30.05.2013.

PAES, Anselmo. "Corpo e sagrado na busca pela saúde: alcoólicos anônimos, espiritismo e práticas e objetos votivos". In: $28^{a}$ Reunião Brasileira de Antropologia - $28^{a}$ RBA, São Paulo, 2012. Anais da 28 RBA, v.1, Brasília: ABA, 2012. Disponível em: http://www.abant.org.br/conteudo/ANAIS/CD_Virtual_28_RBA/programacao/grupos_trabalho/ artigos/gt63/Anselmo\%20do\%20Amaral\%20Paes-.pdf. Acesso em 04/03/2013.

PANTOJA, Vanda. Negócios sagrados: reciprocidade e mercado no Círio de Nazaré. Dissertação de Mestrado. Belém: UFPA, 2006.

SARÉ, Latif. “A corda dos promesseiros do Círio de Nazaré”. In: FIGUEIREDO, Silvio (Org.). Círio de Nazaré, festa e paixão. Belém: EDUFPA, p. 79-89. 2005.

SILVA, Maria Augusta Machado da. Ex-votos e orantes no Brasil: leitura museológica. Rio de Janeiro: Museu Histórico Nacional, 1981.

SILVEIRA, Flavio Leonel Abreu da. "A paisagem como fenômeno complexo, reflexões sobre um tema interdisciplinar". In: ; CANCELA, Cristina Donza (Orgs.). Paisagem e cultura. Dinâmicas do patrimônio e da memória na atualidade. Belém: EDUFPA, p. 71-83. 2009.

STALLYBRASS, Peter. “A vida social das coisas: roupas, memória, dor”. In: de Marx: roupas, memórias, dor. $3^{\mathrm{a}}$ Ed. Belo Horizonte: Autêntica Editora, p. 7-38. 2008. . O casaco

Recebido em: 15/09/2013 Aprovado em: 11/11/2013 